\section{Somatic Embryogenesis and Plant Regeneration from Muscadine Grape Leaf Explants}

\author{
Carol Robacker \\ Department of Horticulture, Georgia Station, Griffin, GA 30223-1797
}

Additional index words. grapevine, tissue culture, Vitis rotundifolia

\begin{abstract}
Immature leaf laminae and petioles of 'Regale' and 'Fry' muscadine grapes (Vitis rotundifolia Michx.) were cultured on Nitsch and Nitsch (NN) medium supplemented with 9.0 $\mu \mathrm{M}$ 2,4-D and 4.4 $\mu \mathrm{M} \mathrm{BA}$, and gelled with agar. Callus and original explant tissues were transferred to $\mathrm{NN}$ medium containing $10.7 \mu \mathrm{M}$ NAA and $0.9 \mu \mathrm{M}$ BA to proliferate embryogenic callus, which, when transferred to $\mathrm{NN}$ medium without growth regulators, yielded globular embryos. The embryos matured and germinated after being subcultured to fresh medium without growth regulators. Somatic embryogenesis incidence was greater from petioles than laminae: $90 \%$ of 'Regale' and $50 \%$ of 'Fry' petioles formed embryos, compared with $14 \%$ and $2 \%$ of laminae, respectively. Culturing germinated somatic embryos on NN medium with $1 \mu \mathrm{MBA}$ enhanced shoot growth. Regenerated plants flowered and appeared morphologically normal. Chemical names used: $\mathrm{N}$-(phenylmethyl)- $1 \mathrm{H}$-purin-6-amine (BA); 2,4-dichlorophenoxyacetic acid (2,4-D); $\alpha$ - naphthaleneacetic acid (NAA).
\end{abstract}

Somatic embryogenesis is a rapid propagation method and an important tool in making genetic improvements using molecular and cellular techniques (Bajaj, 1986). Several Vitis spp. have produced somatic embryos from various explant tissues, including anthers, ovules, zygotic embryos, shoots, leaves, petioles, and flowers (Krul and Worley, 1977; Mullins and Srinivasan, 1976; Stamp and Meredith, 1988a, 1988b). However, topreserve cultivar identity, explants must be derived from tissue that is genetically identical to that of the cultivar (Bajaj, 1986).

Muscadine grape is an important fruit crop in the southeastern United States. Although somatic embryogenesis from immature, zygotic embryos of muscadine grapes has been reported (Gray, 1992), embryos are needed from clonal mature tissue. Preliminary studies have obtained somatic embryos and plants from leaf tissue of one muscadine grape cultivar, although embryogenesis incidence was low (Robacker and Lane, 1987). This report describes a method for high-frequency somatic embryo induction from leaf tissue in two muscadine grape cultivars.

Immature leaves, 5 to $20 \mathrm{~mm}$ in diameter, were collected from greenhouse-grown 'Regale' and 'Fry' plants. The leaves were washed in running tap water for 1 to $2 \mathrm{~h}$, disinfested for $20 \mathrm{~min}$ in a $0.05 \%(\mathrm{v} / \mathrm{v}) \mathrm{NaClO}$ solution with

Received for publication 16 Apr. 1992. Accepted forpublication 21 Sept. 1992. A contribution of the Univ. of Georgia Agr. Expt. Sta., Georgia Station, Griffin. This research was supported by state and Hatch Act funds allocated to the Georgia Agr. Expt. Sta. I gratefully acknowledge the technical assistance of Betty Robicheaux. The cost of publishing this paper was defrayed in part by the payment of page charges. Under postal regulations, this paper therefore must be hereby marked advertisement solely to indicate this fact. a few drops of Tween 20, and rinsed three times, $\approx 15 \mathrm{sec} / \mathrm{rinse}$, in sterile distilled water. Leaf laminae $>5 \mathrm{~mm}$ were cut into 5 - to $8-\mathrm{mm}$ diameter pieces, each containing part of a vein. The abaxial sides of the laminae were pressed against the medium's surface. The petioles were collected from expanded 60- to 100 -mm-diameter leaves located on nonwoody stems of greenhouse-grown 'Regale', 'Fry', 'Golden Isle', 'Nesbitt', and 'Triumph'. The petioles were disinfested by washing them in running tap water for $15 \mathrm{~min}$, soaking them for $20 \mathrm{~min}$ in a $1 \%(\mathrm{v} / \mathrm{v}) \mathrm{NaClO}$ solution containing several drops of Tween 20, and rinsing them three times, $\approx 15 \mathrm{sec} /$ rinse, in sterile distilled water. Petiole ends were removedand petioles were cut into 15-mm-long segments, which were placed horizontally on the culture medium's surface. Cultures were maintained at 27 to $30 \mathrm{C}$, with $16 \mathrm{~h}$ of light provided by $110-\mathrm{W}$ wide-spectrum fluorescent lamps (70 $\left.\mu \mathrm{mol} \cdot \mathrm{m}^{-2} \cdot \mathrm{s}^{-1}\right)$.

The basal medium used to initiate embryogenie callus, obtain callus proliferation, and promote somatic embryo maturation consisted of Nitsch and Nitsch (1969) salts and vitamins, $20 \mathrm{~g}$ sucrose/liter, $8 \mathrm{~g}$ purified agar/liter (Sigma, St. Louis), and growth regulators as described below. The $\mathrm{pH}$ was adjusted to 5.5 with $1 \mathrm{~N}$
$\mathrm{NaOH}$ before adding the agar. The medium was dispensed in 8-ml aliquots into $25 \times 95$ mm glass scintillation vials capped with clear Magenta caps (Magenta Corp., Chicago), and autoclaved for $20 \mathrm{~min}$ at $121 \mathrm{C}$.

To determine the effect of growth regulators on embryogenic callus initiation from 'Regale' and 'Fry' laminae, 42 growth regulator combinations were tested over 1 year. Due to time and plant material limitations, all combinations were not tested at the same time but were divided into four experiments as follows: 1) 4.5, 9.0, or $18.1 \mu \mathrm{M} 2,4-\mathrm{D}$ combined with $4.4,8.9$, or $17.8 \mu \mathrm{M} \mathrm{BA}$; 2) 5.4, 10.7, 21.5. or $43.0 \mu \mathrm{M}$ NAA combined with $4.4,8.9$, or $17.8 \mu \mathrm{M} \mathrm{BA}$; 3 ) 4.5 or $9.0 / \mu \mathrm{M} 2,4-\mathrm{D}$ combined with 4.6, 9.3, or $18.6 \mu \mathrm{m}$ kinetin; and 4) 18.1 $\mu \mathrm{M} 2,4-\mathrm{D}$ or $5.4,10.7$. 21.5, or $43.0 \mu \mathrm{M}$ NAA combined with $4.6,9.3$, or $18.6 \mu \mathrm{M}$ kinetin. At least 20 lamina pieces werecultured on each medium. Media containing 4.5 or 9.0 $\mu \mathrm{M} 2,4-\mathrm{D}$ and 4.4 or $8.9 \mu \mathrm{M}$ BA were retested in three additional experiments, again with at least 20 lamina pieces on each medium.

Two studies were conducted using petioles as explants. The medium used for callus initiation contained $9.0 \mu \mathrm{m} 2,4-\mathrm{D}$ and $4.4 \mu \mathrm{M}$ BA. In the first study, 10 petioles and 40 laminae of 'Regale' were cultured, and in the second study, 50 petioles each of 'Regale', 'Fry', 'Golden Isle', 'Nesbitt', and 'Triumph' were cultured.

After 5 to 7 weeks on the initiation medium, the entire explant (callus and lamina or petiole) was transferred to basal medium supplemented with $10.7 \mu \mathrm{M}$ NAA and $0.9 \mu \mathrm{M}$ BA for callus proliferation. Following culture for 4 to 7 weeks, the calli were observed for the presence of somatic embryos, and the entire explants were transferred to basal medium without growth regulators. Cultures were observed weekly for the presence of somatic embryos. After 6 to 8 weeks, the cultures were transferred to fresh medium without growth regulators. At transfer, embryos and embryogenie callus were isolated from nonembryogenie callus and cultured separately. To maintain embryogenic cultures, embryogenic callus and somatic embryos were transferred every 6 to 8 weeks to fresh medium without growth regulators.

To determine whether the callus proliferation medium (basal medium with $10.7 \mu \mathrm{M}$ NAA and $0.9 \mu \mathrm{MBA}$ ) was essential for somatic embryogenesis, an experiment was conducted in which 'Regale' laminae were cultured on initiation media containing 4.5 or
Table 1. Effect of initiation media containing various concentrations of 2,4-D and BA on embryogenesis from laminae or petioles of 'Regale' and 'Fry' muscadine grape. Explants were cultured on initiation media for 5 to 7 weeks. Final data were collected 6 months after culture initiation.'

\begin{tabular}{|c|c|c|c|c|c|c|c|c|c|c|c|c|}
\hline & \multicolumn{6}{|c|}{ Regale } & \multicolumn{6}{|c|}{ Fry } \\
\hline & \multicolumn{4}{|c|}{ Laminae } & \multicolumn{2}{|c|}{ Petioles } & \multicolumn{4}{|c|}{ Laminae } & \multicolumn{2}{|c|}{ Petioles } \\
\hline \multirow{3}{*}{$\begin{array}{l}\mathrm{BA} \\
\left(\mu_{\mathrm{M}}\right)\end{array}$} & \multicolumn{12}{|c|}{$\overline{2,4}-\mathrm{D}(\overline{\mu \mathrm{M})}$} \\
\hline & \multicolumn{2}{|c|}{4.5} & \multicolumn{2}{|c|}{9.0} & \multicolumn{2}{|c|}{9.0} & \multicolumn{2}{|c|}{4.5} & \multicolumn{2}{|c|}{9.0} & \multicolumn{2}{|c|}{9.0} \\
\hline & $\widehat{\%}$ & $\overline{\mathrm{n}^{y}}$ & $\%$ & $\bar{n}$ & $\%$ & $\bar{n}$ & $\overrightarrow{\%}$ & $\bar{n}$ & $\overline{\%}$ & $\bar{n}$ & $\overline{\%}$ & $\bar{n}$ \\
\hline 4.4 & 10 & 79 & 19 & 62 & 91 & 32 & 3 & 30 & 2 & 58 & 50 & 24 \\
\hline 8.9 & 14 & 28 & 14 & 77 & -- & --- & 0 & 19 & 0 & 27 & --- & --- \\
\hline
\end{tabular}

Laminae: data are combined results of four runs; petioles: data are combined results of two runs. ${ }^{y} n=$ Number of noncontaminated explants cultured. 

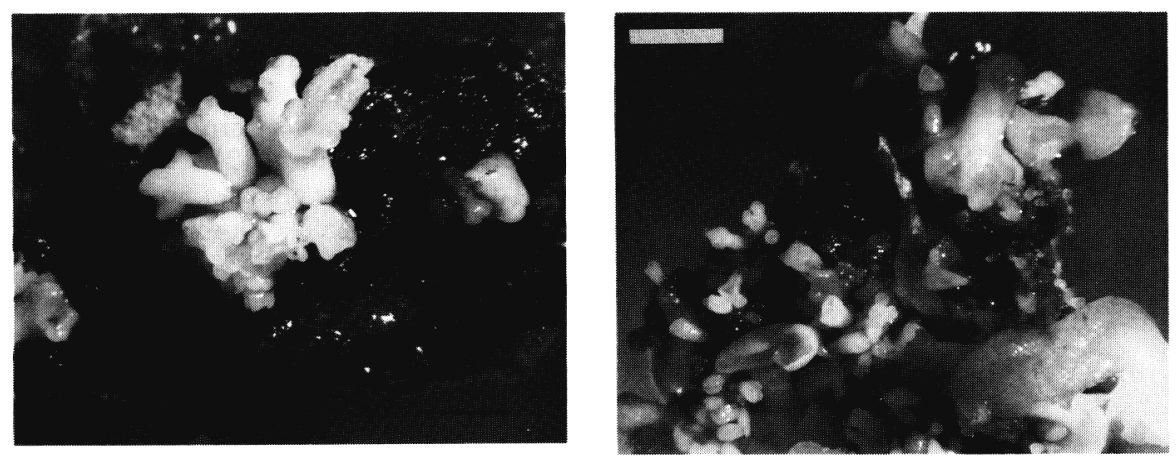

Fig. 1. Somatic embryos developing from darkbrown callus from a 'Regale' muscadine grape petiole $(\mathrm{bar}=0.8 \mathrm{~mm})$

$9.0 \mu \mathrm{M} 2,4-\mathrm{D}$ and 4.4 or $8.9 \mu \mathrm{M}$ BA. After 6 weeks, half of the explants was transferred to callus proliferation medium and half to basal medium without growth regulators. Cultures were observed weekly for somatic embryos, and after 7 weeks, all cultures were transferred to a medium without growth regulators. Cultures were again monitored weekly for embryogenesis.

Contamination varied among experiments from $10 \%$ to $60 \%$, resulting in 11 to 77 noncontaminated explants on each initiation medium. Callus formation was slow; the surface of the explants was three-fouths to fully covered with a thin layer of callus 5 to 6 weeks after culture initiation. The callus was mostly hard and difficult to scrape from the explants. 'Regale' callus was green-brown with white on top, while 'Fry' callus was yellow-gray. After the explants were transferred to the second medium (callus proliferation medium), callus size increased rapidly, thickly covering the explant and growing out onto the medium. With each treatment, some explants had uniform callus, usually dark brown or gray. Other explants had heterogeneous callus; some sectors were green and friable, other sectors were white, yellow, dark brown, or gray. The darkbrown and gray calli were mostly friable, with hard spherical cell masses. White, globular embryos were sometimes present among the dark-brown or gray callus. Among the explants that formed somatic embryos in these experiments, $10 \%$ of those from laminae and $50 \%$ of those from petioles were first observed on this second culture medium. Most somatic embryos from callus on laminae were noted after transferring the callus to the basal medium without growth regulators.

In the experiment that was conducted to determine whether callus proliferation medium was essential for embryogenesis, $40 \%$ of somatic embryogenesis occurred from calli that were transferred directly from the initiation medium to the medium without growth regulators. However, omitting the callus proliferation medium reduced embryogenic callus size and, consequently, the number of embryos that was obtained. Srinivasan and Mullins (1980) also observed that using a callus proliferation medium greatly increased the number of embryos from $V$. vinifera $\mathrm{L}$. ovules.

Only six of the 42 initiation media tested
Fig. 2. 'Regale' muscadine grape somatic embryos in various developmental stages (bar $=0.8 \mathrm{~mm}$ ).

promoted embryogenesis from 'Regale' laminae. Four of these media contained BA and 2,4-D (Table 1). Replicating these treatments over time revealed considerable variation among experiments. For example, embryogenesis on media supplemented with $4.5 \mu \mathrm{M}$ 2,4-D and $4.4 \mu \mathrm{M}$ BA ranged from $3 \%$ to $33 \%$. The other two media that supported embryogenesis contained $18.6 \mu \mathrm{m}$ kinetin and $18.1 \mu \mathrm{M}$ 2,4-D or $43 \mu \mathrm{m}$ NAA. Embryogenesis was observed on $6 \%$ and $4.5 \%$, respectively, of the explants. Only two of the media supported embryogenesis from 'Fry' laminae (Table 1).

There was a much higher embryogenesis incidence from petioles than from laminae for the single medium tested with petioles (Table 1). Somatic embryos formed from $40 \%$ of the 'Regale' petioles in the first petiole experiment. In the second experiment, somatic embryos were produced on all 'Regale' and half of 'Fry' petioles. No embryos were obtained from 'Golden Isle', 'Nesbitt', or 'Triumph' petioles.

'Regale' and 'Fry' embryos developed from callus that was dark brown, friable, and apparently necrotic (Fig. 1). Gray (1992), in studies on somatic embryogenesis from zygotic muscadine grape embryos, also observed that embryogenic calli emerged when the surrounding callus declined. Similarly, Krul and Worley (1977) found that somatic embryos from petioles and flower clusters of the French hybrid grape 'Seyval' were adjacent to necrotic tissues. These results are in contrast to the work of Stamp and Meredith (1988a), who observed somatic embryogenesis directly from $V$. vinifera and $V$. rupestris Scheele leaves.

Globular somatic embryos proliferated from callus and through secondary embryogenesis from the surface of other somatic embryos. Following each transfer to fresh medium without growth regulators, some of the globular embryos developed into heart and torpedo stages and finally germinated (Fig. 2). In one study, 'Regale' somatic embryos from seven culture vials were counted and evaluated following a 3-week culture cycle. Each vial had been inoculated with a mass of embryogenie callus and embryos $\approx 10 \mathrm{~mm}$ in diameter. The mean number of embryos per culture vial was $308 ; 56 \%$ of the embryos was globular, $27 \%$ heart-shaped, $1 \%$ torpedo-shaped, and $16 \%$ had germinated. Most germinated em-

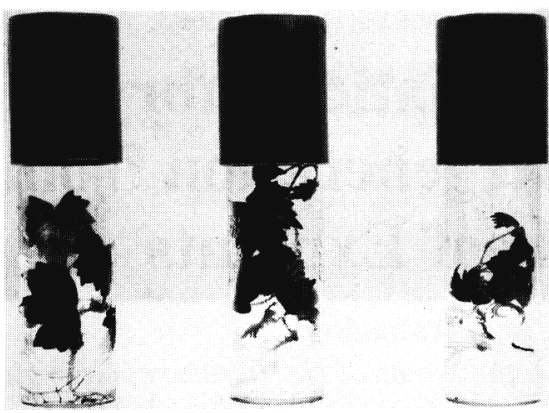

Fig. 3. 'Regale' muscadine grape plantlets from somatic embryos.

bryos had a radicle, hypocotyl, and cotyledons. Of these, $64 \%$ had two cotyledons, $17 \%$ had more than two, and the remainder had either no or fused cotyledons. Those with fewer than two cotyledons usually failed to form plantlets. Transferring germinating 'Regale' somatic embryos to $100 \times 20$-mm petri dishes or vials containing basal medium supplemented with $1 \mu \mathrm{M}$ BA promoted shoot elongation in $\approx 20 \%$ of the embryos (Fig. 3). Enhanced shoot development was also observed in $V$. longii Prince cultured on $1 \mu \mathrm{M} \mathrm{BA}$ (Gray and Mortensen, 1987).

Germinated embryos that grew shoots and roots were placed in a commercial potting mix (Pro Gro 200; Gro-Bark, McCormick, S.C.) under $65 \%$ shadecloth and intermittent mist. Misting duration and frequency was gradually reduced from $10 \mathrm{sec} / 4 \mathrm{~min}$ to $4 \mathrm{~s} \cdot \mathrm{h}^{-1}$, and after 4 weeks, the plants were removed and grown under ambient greenhouse conditions. More than 20 'Regale' plants were grown to flowering, and all appeared normal.

This is the first report, to my knowledge, of somatic embryogenesis from mature vegetative muscadine grape tissues. In this study, a straightforward protocol for inducing somatic embryogenesis from petiole tissue has been described. Petioles are advantageous as explants because they are readily available, easily established in culture, and, in the case of 'Regale' and 'Fry', produce a high rate of somatic embryogenesis. Further, petioles maintain cultivar identity, an important consideration in using somatic embryogenesis for propagation or genetic manipulation. The techniques applied in this study were apparently genotype-specific, because only two of the five cultivars tested formed somatic embryos. Further studies are needed to obtain somatic embryos from other cultivars and to increase the percentage of somatic embryos that convert to plants.

\section{Literature Cited}

Bajaj, Y.P.S. 1986. Biotechnology of tree improvement for rapid propagation and biomass energy production, p. 1-23. In: Y.P.S. Bajaj (ed.). Biotechnology in agriculture and forestry 1: Trees I. Springer-Verlag. Berlin, Heidelberg, Germany.

Gray, D.J. 1992. Somatic embryogenesis and plant regeneration from immature zygotic embryos of muscadine grape (V itis rotundifolia) cultivars. Amer. J. Bot. 79:542-546. 
Gray, D.J. and J.A. Mortensen. 1987. Initiation and maintenance of long term somatic embryogenesis from anthers and ovaries of Vitis longii 'Microsperma'. Plant Cell Tissue Organ Culture 9:73-80.

Krul, W.R. and J.F. Worley. 1977. Formation of adventitious embryos in callus cultures of 'Seyval' a French hybrid grape. J. Amer. Soc. Hort. Sci. 102:360-363.

Mullins, M.G. and C. Srinivasan. 1976. Somatic embryos and plantlets from an ancient clone of the grapevine (cv. Cabernet-Sauvignon) by apomixis in vitro. J. Expt. Bot. 27:1022-1030.

Nitsch, J.P. and C. Nitsch. 1969. Haploid plants from pollen grains. Science 163:85-87.

Robacker, C.D. and R.P. Lane. 1987. Effect of media and gelling agent on micropropagation and somatic embryogenesis of muscadine grape. HortScience 22(5):1118. (Abstr.)

Srinivasan, C. and M.G. Mullins. 1980. High-fre- quency somatic embryo production from unfertilized ovules of grapes. Scientia Hort. $13 ; 1245-252$.

Stamp, J.A. and C.P. Meredith. 1988a. Somatic embryogenesis from leaves and anthers of grapevine. Scientia Hort. 35:235-250.

Stamp, J.A. and C.P. Meredith. 1988b. Proliferative somatic embryogenesis from zygotic embryos ofgrapevine. J. Amer. Soc. Hort. Sci. 113:941945 . 